\title{
Techne and Techniques for Engaging in a Socially Complex World \\ Lorraine Dodd
}

This paper contains information that is Cranfield University copyright.

\begin{abstract}
This paper addresses the challenge for Operational Research (OR) in extending out from traditional forms of modelling towards a more relational form of modelling. The challenge comes from OR practice becoming more transformative in nature, which puts more emphasis on reflective practice, people and relationships. Staged Appreciation is proposed as an overall guiding framework and selected illustrative techniques are presented for engaging with social complexity; so-called "wicked" problems. Systems Thinking techniques, guided by Staged Appreciation add an insightful new dimension to knowledge sharing for understanding, and for reflecting upon the intricacies involved in socially complex situations.
\end{abstract}

There are analytical advantages of standing apart from complexity. Staged Appreciation complements this analytical standpoint by asking analysts to take a more reflective view of their own working relationships, being more $a$ part of the socially complex problem as well as standing apart from it. Staged Appreciation offers a reflective framework for working with Systems Thinking techniques and together they complement traditional practice. The proposal and suggestions aim to support analysts to adopt a more reflective and relational view of a complex problematic situation in order to see it 'as a whole'. The paper draws lessons from holism, reflective practice and subjective analysis.

Keywords: Soft Systems, Methodology, Practice of OR, Multi-Objective, Heuristics. 


\section{Background to identify the practice gap}

Over several years of running courses on systemic thinking and reflective practice for complex situations, attended by government analysts, it has become more apparent that analytical skills might benefit from a more subjective approach. The situations tend to be more socially and relationally complex (Ulrich and Dash, 2013), and any interventions and proposed solutions may therefore need to be "clumsy" resolutions (Thompson, 2008).

As "OR projects have become increasingly participative" (Ormerod, 2008), and the projects that analysts are involved in have become more interconnected, there may be a call for more reflective practice. This asks the analyst where they stand in relation to others involved in the situation. This perhaps calls for a second look at "OR competencies" where analysts need to have an "ability to self-assess" (Ormerod, 2013).

\section{Introduction to socially complex situations}

Any problem that has you, as an analyst, involved in it, by definition has you, the analyst, as a part of the problem. If OR is to address socially complex problems then there may be need for some complementary techniques that will help to:

- Look at people as people and not as "things" (e.g. nodes in a network, resources);

- Being subjective as well as objective; for example, seeing situations from a subject's perspective as well as from an analytical perspective;

- Broaden focus so that compromise solutions might be found that go beyond the usual objective indicators and measures that lead only to a single-point optimal.

- See the problem from different perspectives (e.g. so what seems to be "the best" from one perspective can be resolved for situations with multiple stakeholders)

- Highlight the interactions between things and events; and, more importantly, the intricacy of relationships between people (i.e. couplings, social bonds);

- See the problem as a whole.

Today's problematic situations are becoming more complex (Bar Yam, 2005), where increasing complexity tends to be attributed to an unbounded number of elements and interactions and an increasing rate of events. Previous papers on so-called "wicked problems" (Churchman, 1967), (Roberts, 2000) and previous studies (Dodd and Alston, 
2009) have suggested that complexity has another important dimension, which relates to the increasing intricacy of couplings and inter-relationships. It is the nature of this inherent interrelational intricacy that forms the context for this paper.

When problems are looked at objectively, they tend to be viewed in terms of the quantitative dimension of complexity. The inherent social and personal complexity of human systems (Vickers, 1983) is not being addressed. So the first question that this paper poses is: "What is available to help OR analysts appreciate more fully the intricate, personal and relational nature of the complexity in the situation as a whole?"

This paper proposes Staged Appreciation as a form of techne, which captures the essence of what it is to master a skill, and as such could be used as a guiding check-list as OR analysts work with people through complex problems. This check-list approach is in the spirit of Dr Atul Gawande, as in his 2014 Reith Lectures he proposed such an approach to aid with "the messy intersection of science and human fallibility".

Staged Appreciation (Dodd, Alston and Stamp, 2010) follows six inter-related stages:

- Where people are: this acknowledges that 'where people are' is the most important consideration, and that this positioning of people has many aspects; so it could be in socio-geographical/demographic terms, and socio-cultural/political terms and it could be in terms of their capacity for sensing the extent of the situation and for making sense of the unbounded complexity of the situation.

- Open-eyes/open-mind: explicitly addresses how people might be approaching their sensing and sense-making; so, for example, if people are only looking at the predefined indicators or parameters and using extrapolation of past indicator-based trends, then this closed-eyes/closed-mind approach, in itself, forms a large part of the broader problematic situation.

- Belief and surprise: elicits what people believe through asking what might surprise them (see Figure 1); so, for example, if people have been greatly surprised by the consequences of a considered decision, (e.g. believe that use of method A will help to solve problem $\mathrm{X}$ ) then they are more likely to openly appreciate and reflect on their previously held belief about what could happen and adapt accordingly. 
- Choice-making and choose-ables: suggests that people's choose-ables tend to limit and colour their views on a situation; so, for example, if people can only consider or countenance two ways forward, then the situation will be viewed in black and white or 'us-them' terms. If people can be helped to see beyond their current or comfortable ways forward and to relate to others' choose-ables, then this proffers more open understanding of the potential benefits of novel options for resolution.

- Focus and preference: are intricately related to belief and choose-ables; so, if all of these can be openly appreciated then 'where people are' (especially in terms of openeyes and open-mind) can be addressed as being part of the problem situation. This applies directly to the analyst or the problem structurer or facilitator.

- Multi-perspectives: can now be appreciated with a richer understanding of the diverse range of people's views, and of people's deeply held lines of perspective, that can be hidden deep within a problematic situation, when ways of being and doing (i.e. their Weltanschauungen, as discussed later) are dear to people's hearts, minds, behaviours and lives.

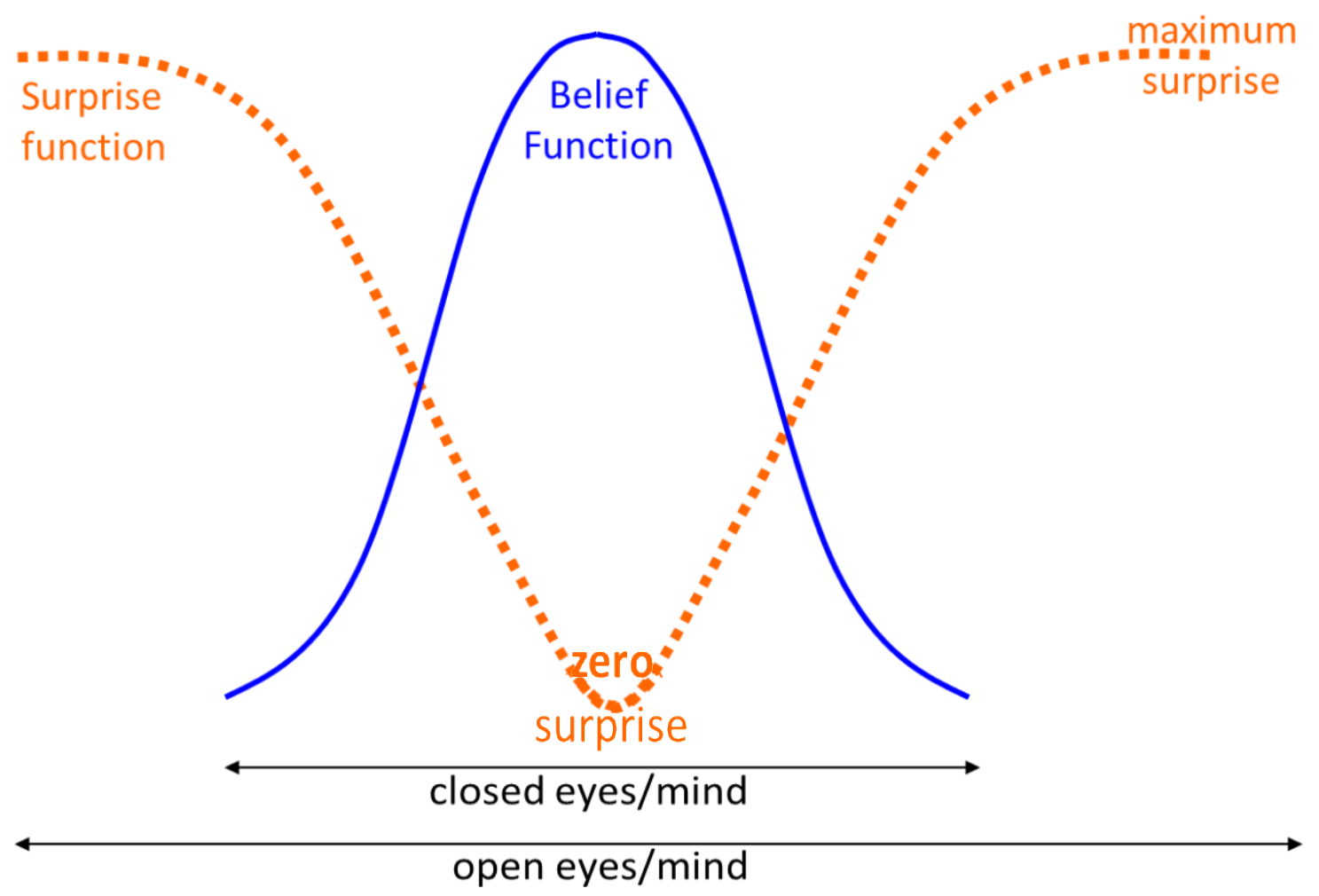

Figure 1: Surprise as the inverse function of belief relating to open-eyes/open-mind. 
There are other useful frameworks such as Critical Systems Heuristics (in Ulrich, 2003) to show how holding to a single analytical measure of success can dominate analysis, such that it determines problem-solutions and limits perspectives. CSH can mitigate against particular measures of success (MoS) dominating analyses by making the MoS explicit and linking the MoS directly to those involved, who may be working through power dynamics to serve their own interests rather than seekng shared interests. CSH is now discussed further in relation to Staged Appreciation, Problem Structuring Methods (PSM) and System of Systems Methodology (SOSM).

\section{A view of the landscape}

The academic and practice-based landscape of the development of OR and Management Science (OR/MS) is comprehensively reviewed in (Jackson, 2006), in which the framework for positioning Problem Structuring Methods is defined using categories of problem: simple or complex; set against natures of participation: unitary, pluralist, coercive (adapted from (Flood and Jackson, 1991)). Rather than arrange methods and approaches as a segmented framework, which assumes a problem structurer's categorisation of the landscape, Figure 2 here depicts a nested view of that landscape. Following from (Ulrich, 2017), the types of questions posed in each layer are presented to show how Staged Appreciation relates to $\mathrm{CSH}, \mathrm{PSM}$ and OR/MS respectively.

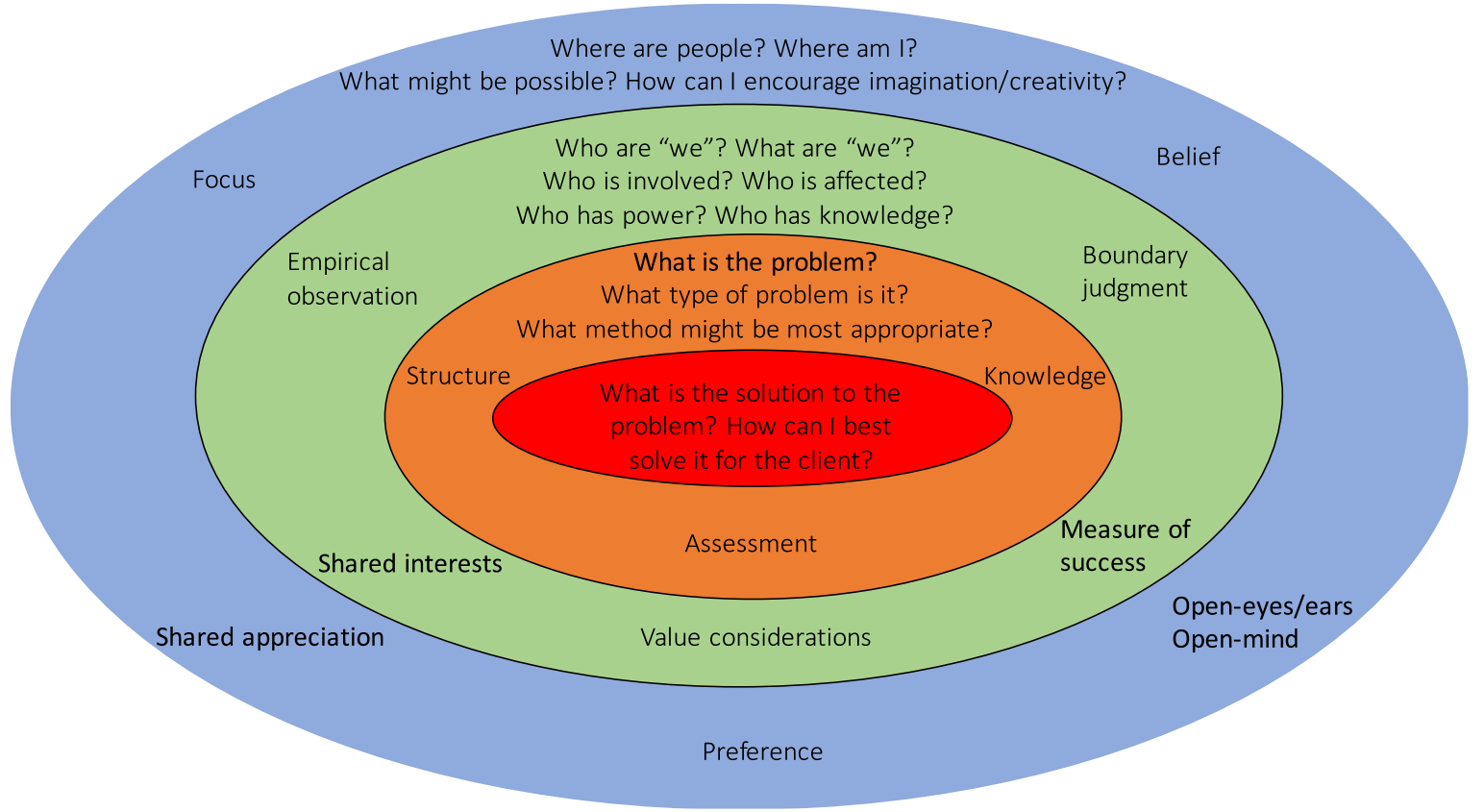

Figure 2: Staged Appreciation working through and within CSH, reflectively supporting PSM into OR/MS. 
Jackson (in Jackson, 2006) also discusses Morgan's metaphors, listing them in terms of seeing "organisations as". Alternatively, and more relationally-speaking, this nested view distinguishes relational boundaries (as drawn by the ellipses in Figure 2) according to how the nature of organisation (i.e. what lies between) is being viewed or imagined when working in each of the layers. The inner layer is where OR/MS sees organisation as purposive couplings (e.g. cause-effect). The next layer is where PSM sees organisation as structural couplings. The next layer is where CSH sees organisation as cultural and political relationships. The next layer is where Staged Appreciation sees organisation as interpersonal. Staged Appreciation subsumes, and so works around and within, the other layers. Jackson (in Jackson, 2006) suggests an additional "carnival" metaphor; Staged Appreciation might suggest organisation as dance, where each person is an individual, each appreciating the dynamic relationship with opportunity for creativity and innovation.

\section{Stakeholder Perspectives and Soft OR}

Typically, designing of systems solutions is generally supported by OR advice using a well defined set of objectives, against which the system effectiveness can be measured. The OR analytical perspective provides objective measurements of effectiveness for the systems concepts under consideration. These systems concepts, however, tend to involve a diverse range of stakeholders, often each with a different perspective on value or success. So what might be 'best' or 'better' from one stakeholder's perspective may not be best or better (or even good) from another's perspective. These stakeholders are usually inter-related, and yet the nature of these inter-relationships is rarely taken to be an integral part of the problematic situation. In complex problems it may be the nature of those inter-relationships that lies at the conditional heart of a possible solution or resolution.

Checkland's Soft Systems Methodolgy (SSM) in (Checkland and Scholes, 2001) goes some way to addressing the stakeholder perspectives; however, the nature of SSM's "CATWOE" embodies a "T for Transformation" that is based on a single desired state change; also with an assumed "C for Customer" stakeholder relationship. (Seagriff and Lord, 2011) summarise the philosophy behind SSM as giving "an approach for taking a complex human situation/problem and expressing its core constituent systems in a standard way that is transparent and involves the whole client group". The need for some relational extension is captured in (Williams, 2005): "It is worth noting here that in recent years, some associated 
with Critical Systems Thinking who use SSM have made two very significant changes to CATWOE; (i) They have replaced $\mathrm{C}$ with two concepts; $\mathrm{B}$ for Beneficiaries, and V for Victims (BATWOVE) (ii) B and V can include ideas as well as people. These are highly significant changes that open up new domains for SSM." In addition in CATWOE there is the "W for Weltanschaunng", which is often translated as "worldview" but the German concept embodies preference, focus and belief. It is these important W-extensions (including those of the OR analyst) that this paper addresses.

\section{Staged Appreciation as Techne}

The work to develop Staged Appreciation as a reflective framework began with a study of Shackle's approach (Shackle, 1957) to business decisions and intrinsic uncertainty about possible futures. Shackle's three functions of belief, focus and preference are woven together to capture a subjective choice perspective. Shackle's term "choose-able" has been adopted so that choice-making becomes explicit as: "Your list of choosable things has to be constructed or composed by yourself before you can choose". The concept of a choose-able is something imagined, constructed, composed and countenanced by a person to then be put forward by them as an option for decision-making or policy-making. In terms of defining strategy, choose-ables represent the imagined, deemed possible.

A person's three functions and their evolving choose-ables co-work as a dynamic whole. The premise is that, as fallible humans, it is mostly impossible to suspend our preferences and to be open about closely held beliefs. The term "preferences" refers to people's preferred tools and ways of doing things. Preferences and beliefs tend to shape the chooseables from which a solution might be found; all of which focus interest in terms of specific indicators and measures of success. Once such a focus is set, it is difficult to remain open to different perspectives (i.e. other preferences, beliefs, foci of interest, etc) and, as importantly, to other choose-ables. This collective phenomenon is referred to by bomb disposal experts as "fatal baggage" (Sirett and Dodd, 2006), where their belief about the situation, linked to their preferred ways of working, then focused their attention away from reflecting on what else the critical situation might be. The question now becomes:

In what ways might options, minds and eyes remain more open? 
The open-eyes/open-mind $(\mathrm{OE} / \mathrm{OM})$ matrix shown in Figure 3 was developed for the Swedish Strategic Crisis Management Unit following their seminal work (Boin, t'Hart, Stern and Sundelius, 2006). It was presented as part of Staged Apprciation to the Swedish PM Office in 2008, to reflect on surprising critical events in Stockholm when looking at counter-terrorism responses, and later for options to deal with the Assange situation. In addition, it was used in the UK and EU principally to appreciate where people are in terms of their choice-making, sense-making and purpose sharing in the context of public diplomacy. An illustrative case study looks at environmental initiatives by convening a range of stakeholders within a shared interest, and working carefully through an appreciation of 'self' and then relationships that needed to be developed. The case study is covered in detail in the chapter by Hudson and Anstead in (Welsh and Fearn, 2008).

The six stages of Staged Appreciation are illustrated through the case study as follows:

- Where people are: This addressed the positioning of people in personal, organisational and institutional terms. The people here ${ }^{1}$ were members of the public, members of non-governmental organisations (NGOs), local authorities, trade unions, etc. Many had strongly held positions expressed through their opinions on working with others; also on other people's ways of working and of making sense of the problematic situation and its wider context. This had to be made explicit and realised, self-reflectively, by the many different people involved.

- Open-eyes/open-mind: explicitly addresses how those people, as politicians, members of groups or as individuals might be approaching their sensing and sensemaking. If, for example, people are looking through the lens of their ways of being and ways of working then this, in itself, forms a large part of the problematic situation. Using the matrix to ask people where they felt they were, helps with selfreflection and willingness to see others' ways of working and rationales.

- Belief and surprise: Asking what might cause people to be surprised helps them to appreciate their own beliefs about who might be easy to collaborate with. For example: "if we had said to a number of them 'soon you will be working with such

\footnotetext{
${ }^{1}$ There were 330 stakeholder representatives involved in the initial defining of potential actions and then 16,900 people participated in nineteen regional meetings, in which thirty national councils offered views.
} 
and such' they would not have believed it.... Normally critical, NGO and media voices were openly surprised" ( $\mathrm{see}^{2}$ p151 in Welsh and Fearn, 2008);

- Choice-making and choose-ables: Asking explicitly about what people felt were their possible and impossible options for future ways forward helps them to appreciate the limits they were putting on future choices and then to understand that working with others could open-up more options. This important activity of choice-making is an essential key to open-up new working relationships for co-creating ways forward: "to identify and design solutions to their shared problems, exploiting the diversity by their multiple perspectives, experiences, skills and creativity" (see p148 in Welsh and Fearn, 2008);

- Focus and preference: are intricately related to belief and choose-ables and if all of these can be openly appreciated then "where people are" (especially in terms of open-eyes and open-mind) can be addressed as part of the problem situation. For example: "to identify and understand the extent of their shared interests and potential for joint action... within an overall plan in order to deliver agreed outcomes" (see p148 in Welsh and Fearn, 2008);

- Multi-perspectives: can now be more fully and broadly appreciated with a richer understanding of the diverse range of people's views, pre-positioning and rationales for choose-ables: "The consultation managed to convert this shared interest into a shared appreciation that working together could lead to concrete results, and was more likely to do so than each party pursuing its own agenda in isolation." (see p152 in Welsh and Fearn, 2008).

Staged Appreciation and the OE/OM matrix provides a reflective framework that promotes not just knowledge sharing but also shared appreciation of relative feeling, to put focus on where people are, cognitively and epistemologically, in terms of their sensing, sense-making, shared interest and choice-making. This collaborative creating of contextual and relational conditions for such shared appreciation of interests and knowledge can be linked to Nonaka's concept of "Ba" (Nonaka, Toyama and Konno, 2000).

\footnotetext{
${ }^{2}$ In more detail: "Normally critical NGO and media voices were openly surprised that agreement had been reached on sensitive issues such as transport (restrictions on building of highways or airports, further development of the rail network), building (homeowners to be required by law to make homes energy efficient and given funding to do so), energy (the development of renewable energy to be prioritised over that of other energy sources) and agriculture (organic farming to increase from $2 \%$ of cultivated land to $20 \%$; the use of pesticides to be reduced by $50 \%$; the growing of GM organisms to cease)."
} 
The positioning of people (including the OR analyst) in the OE/OM matrix (see Figure 3) is a key reflective stage. The objective problem-solving position is in the bottom-left quadrant of the matrix: closed-eyes and closed-mind $(\mathrm{CE} / \mathrm{CM})$. Here the focus is fixed onto preselected indicators that serve to provide evidence to support the held hypothesis and beliefs about the world (i.e. the mental models). This evidenced form of analysis is essential best practice for problem-solving. The bottom-right, open-eyes/closed-mind (OE/CM) quadrant represents an 'out of model' surprising event, which opens the eyes but then, because of the closed-mind, is often ignored or dismissed as a freak event. Such "black swan" events described in (Taleb, 2008) signal that people's extant 'belief' models need to be questioned and adapted. This mind-opening is challenging when people's professional reputations are at stake, and often 'black swans' are readily dismissed as white swans that have flown through a sooty chimney, so the "all swans are white" model still holds, unquestioned. If minds are opened by the opening of eyes then people can be open to imagining new, alternative ways forward. So for people to be able to be open-eyed and open-minded (OE/OM) they must be open to seeing others' perspectives and also to appreciating other people's choose-ables.

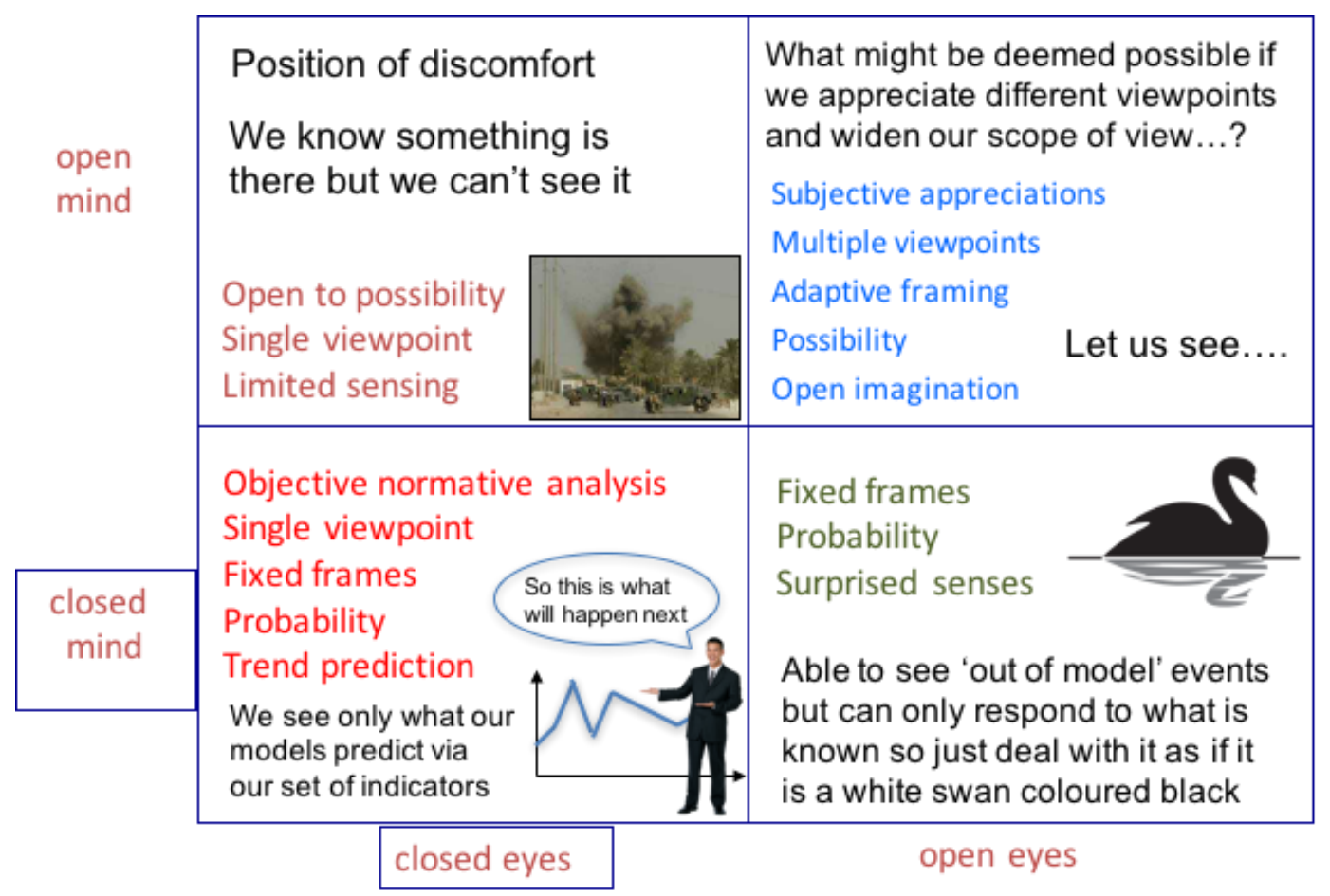

Figure 3: Open-eyes/open-mind matrix to appreciate where people are in terms of sensing and sensemaking (Dodd, Alston and Stamp, 2010). 
The remaining top-left $(\mathrm{OM} / \mathrm{CE})$ quadrant of the matrix is a position of discomfort, when one's mind is open to possibilities (i.e. what might be) yet there is no way of sensing the signals or events. People in OM/CE are prepared for events, and are often working on new ways of sensing with wider awareness more generally; however, this will be disquieting if the institution in which they work has a 'mind' that is closed and imposes closed-eyes policy; as discussed in relation to health workers in (Menzies-Lyth, 1988).

Generally there are two factors associated with closing of minds, eyes and choose-ables:

- Constraints on the means available (e.g. resources, time, etc);

- Restraints on the ways available (e.g. rules, procedures, cultural taboos, etc).

It may therefore be helpful, in the first instance, to make explicit the reasons for these constraints and restraints. The work needed to open up the choose-ables funnel as shown in Figure 4 is essential (but hard) work. This is the key to opening minds and eyes. If the presumed constraints can be made explicit, then it may loosen the presumed restraints. This then provides the cognitive and emotional space for imagination (both futures and options) and different ways of seeing; potentially leading to innovative ways forward.

Specifically, here the 'deeming possible' is linked to people's attitudes to constraints and restraints, so it is a way to capture the essence of strategy as shaping potential for a more openly desired pattern to events, via the dynamic medium of choose-ables construction.

Keeping time and option-space open provides the necessary conditions for OM/OE; however that is not sufficient. The Weltanschauungen also need to be made explicit if at all possible. So people will need support as they are being asked to be explicit about their preferences and beliefs, that are shaping and forming their measures and indicators of success (personal and organisational). 


\section{potential imaginable options}

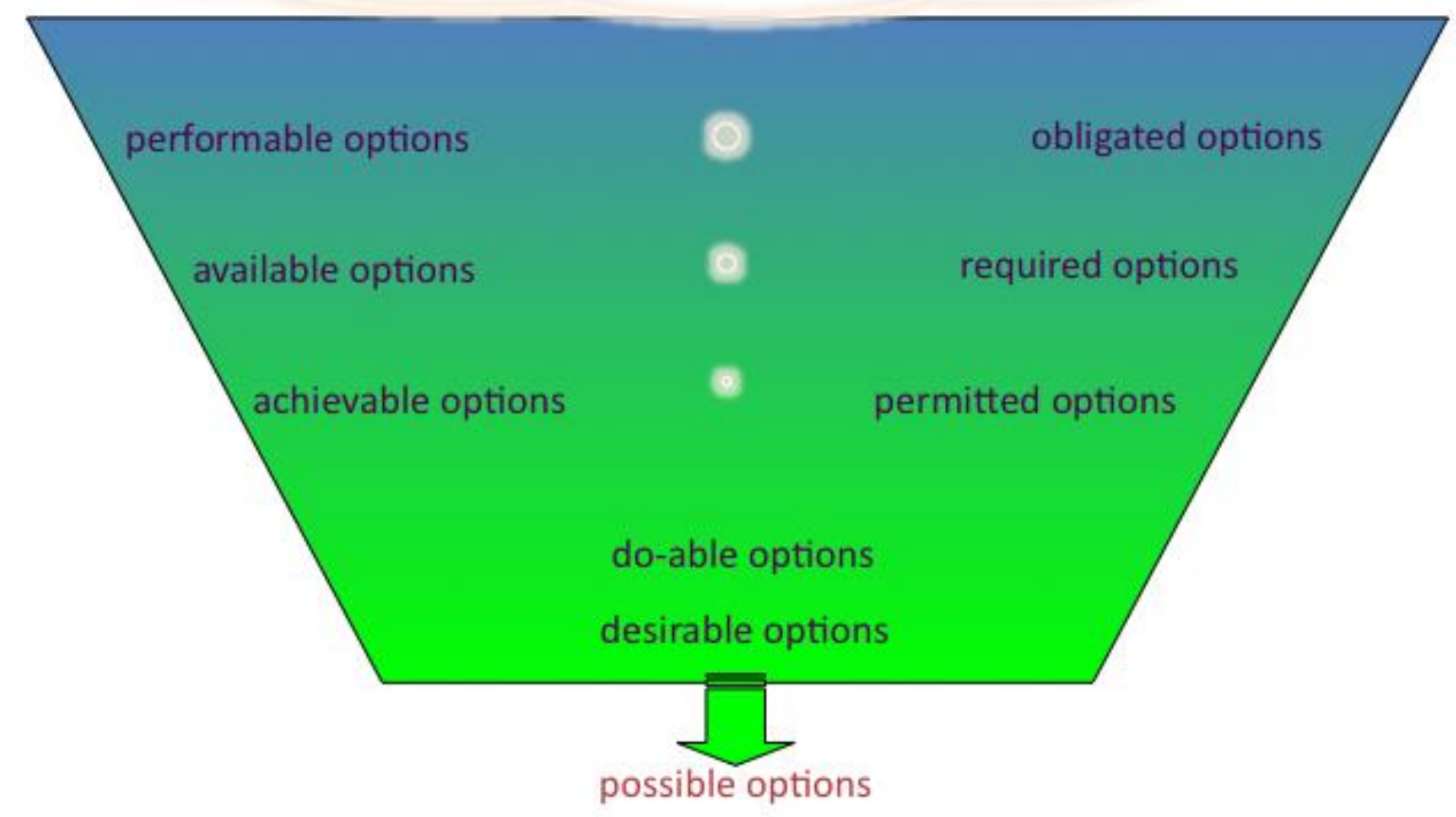

Figure 4: Options funnel to consider "imagined deemed possible" (adapted from Bradshaw, Feltovitch, Jung, Kulkarni, Taysom and Uszok, 2004)

One approach to eliciting preferences perhaps is through Appreciative Inquiry (Cooperrider and Srivastva, 1987); for example, asking people what is working well for them at the moment (or what has worked well in the past) reveals not only what they consider to be 'good' but also what matters to them, revealing the conditions that make the 'good' possible. Shackle refers to a "surprise function" as the inverse of a person's belief 'function'; so asking "what might surprise you if it happened?" and "how much would that surprise you?" helps to reveal the shape and position of tacit beliefs and mental models. All of this is covered through Staged Appreciation.

The paper now selects two techniques in support of OR analysis and problem synthesis.

There are many other techniques for sharing knowledge and understanding of the problem with others involved in the problem (Monks, Robinson and Kotiadis, 2016). The techniques selected draw out different perspectives and also support a synthesis of those perspectives set against a broader view of the problem-solution context. All of this helps to guard against solving the wrong problem; also it helps to work towards a more robust and settled, more 
sustainable, relationship-based resolution rather than the single-point "best" short-term, action-based solution.

\section{Suggested Techniques}

Two selected techniques are suggested here as they specifically address (i) multiple stakeholder perspectives and (ii) opening out to alternative options. There are many other techniques that are currently in use (Heuer and Randolph, 2015). Each technique provides a subtly different way to support open conversations and of sharing of understanding.

\section{Adopting a multi-perspective approach}

The 'pig' model described in (Morgan, 1997) helps people to look at a problem from different perspectives. The first conversation that needs to take place is around what seems to be the central issue of the problematic situation (i.e. the key system of interest). Once this has been agreed (at least to begin with) this issue is drawn centrally as the 'pig' of the problem. The stakeholder persectives can then be developed based on what the 'pig' means to each stakeholder. So for instance, a pig farmer might see a pig as an animal and also as income; a child reading a story book might see a pig as a cute curly-tailed friend. It is on this basis that the stakeholder perspectives (including the analyst's own view) are developed based on that central issue. Quite often it may only be possible to guess or imagine how a particular stakeholder might view the central issue; this in itself is an important unknown (and a CE/CM signal), especially if this is a key stakeholder. Use of organisational metaphor is also important here as it draws out the nature of couplings and inter-relationships (e.g. people talking about levers and mechanisms).

Figure 5 shows an illustrative 'pig' diagram that relates to a potential environmental policy about a restricting airport expansion in rural areas. 


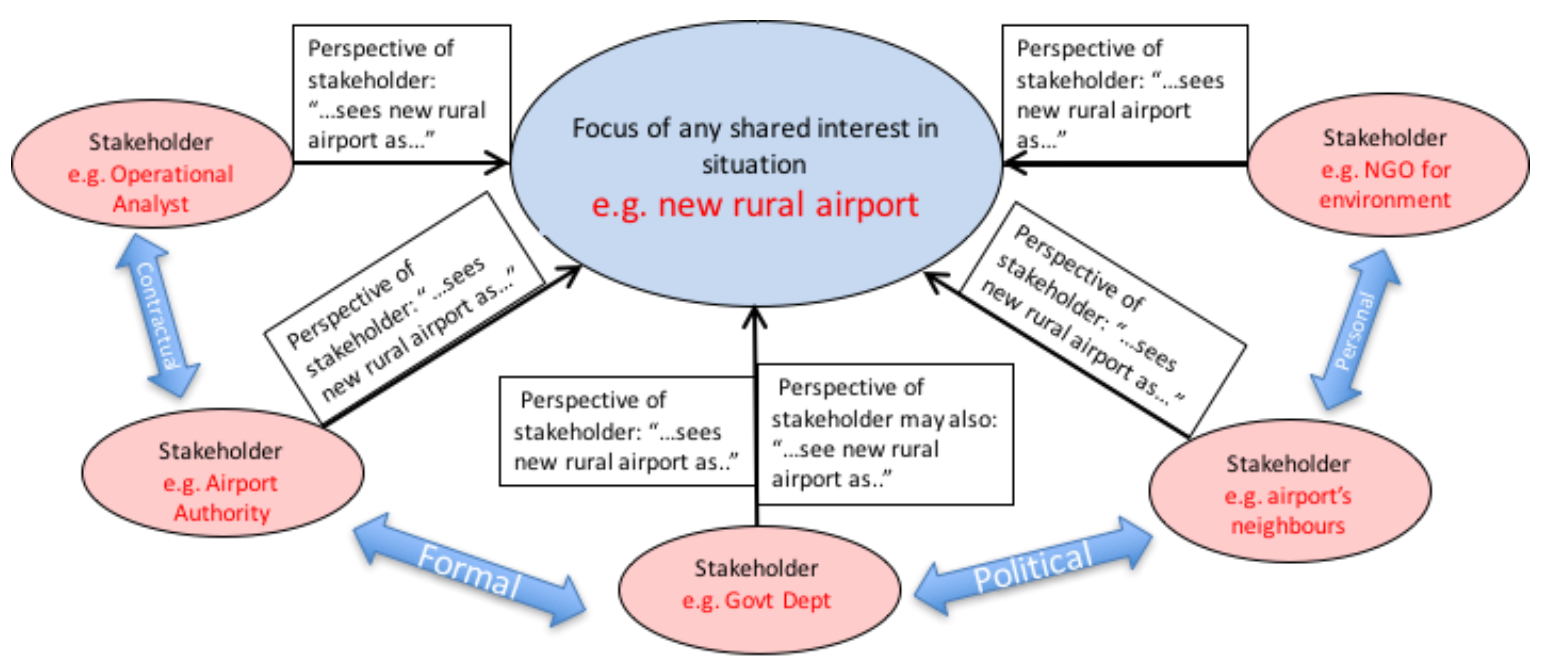

How might each stakeholder be seeing their inter-relationships? In what ways might they be encouraged to imagine possibilities?

Figure 5: Illustrative example of a pig diagram relating to potential for restriction on rural airports.

This can be taken a stage further into a multi-perspective approach to support "what if?" analysis for a proposed policy option or an operational decision (Alston and Dodd, 2009). For example, if one preferred option is to restrict new rural airport development then "new rural airport" could be the initial central issue (i.e. the 'pig'). The multi-perpsective analysis of the 'pig' then considers the following questions:

- What really matters to each of the stakeholders regarding this central issue?

(Form this as a line of perspective (e.g. commercial, environmental) for each key stakeholder.)

- Where people are: how might each stakeholder define their current position on that line of perspective?

- Where might they prefer to be positioned in relation to the policy option?

- What would seem to be making their appreciation of their position better or worse?

- What if anything might you/they do to affect any aspects of the situation?

The final question then leads into a more open exploration of the possible policy options. This may need to be opened-up to explore whether the proposed option is a solution to an illformed, closely bounded problem, and may need an initial focus on shaping relationships. 


\section{Ladder of Abstraction}

The Ladder of Abstraction technique (Isaksen, Dorval and Treffinger, 2010) takes the proposed policy option and explores the space around it in terms of alternatives and also encouraging alternative ways of thinking about the situation; in particular, finding a possible shared purpose or new shared interest. The ladder of abstraction builds from Checkland's PQR analysis (Checkland and Winter, 2005): why? what? how? It explores the contextual alternatives: "why else?", “what else?' and "how else?" based around the opening question: "In what ways might....?". Importantly the open questioning must agree on a problem owner, an active verb and a declared objective; so, this relates to any $\mathrm{CSH}$ thinking that may have been done. For example, if there is a proposed policy to restrict new rural airport development then the opening question would be: In what ways might the government restrict new rural airports?

Figure 6 illustrates the starting state of a ladder of abstraction from which it can be expanded, upwards and outwards, as necesssary to explore a whole range of possibilities. The technique helps analysts to convene with problem owners and other stakeholders to work rigorously yet creatively through their problem space. In many problematic situations there is rarely one problem owner; indeed there may be no single obvious 'owner'. Often the problem has been situated in a solution space, which then tends to dictate the analysis. This brings power relationships to the fore, as one preferred solution may be being pushed. In these situations, power relationships form an important part of the intricacy and need to be made an explicit part of the problematic situation.

The two techniques described have been selected and suggested because they directly support two of the key stages in Staged Appreciation: reflective multiple perspectives and choice-making. There are many other techniques that would be appropriate here. 
Why else?

NEW PROBLEM STATEMENT:
In what ways might they
promote city airports?
WHY ELSE?
To promote city airports
How ELSE?
Re-imagine rural areas
NEW PROBLEM STATEMENT:
re-imagine rural areas?

How else?
Why?

Why else?

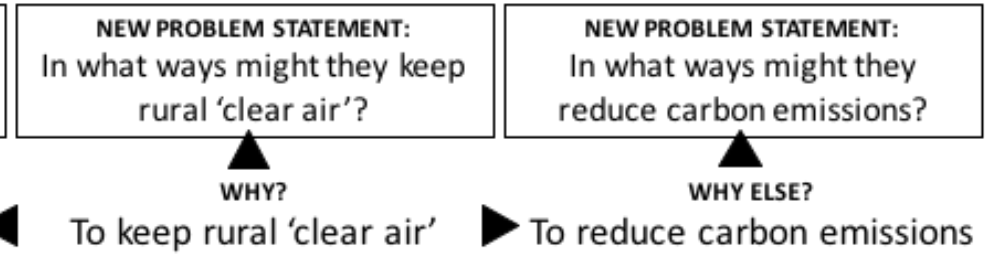

INITIAL PROBLEM STATEMENT:

In what ways might Govt

restrict new rural airports?

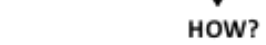

Use other existing airports

NEW PROBLEM STATEMENT:
In what ways might they
use other existing airports?

How?
Re-think airport system

HOW ELSE?

NEW PROBLEM STATEMENT:
In what ways might they
rethink airport system?

Figure 6: Illustrative example of Ladder of Abstraction adapted from (Isaksen, Dorval and Treffinger, 2011)

\section{Discussion}

It is the following two aspects of problem understanding and formulation that Staged Appreciation is addressing: first, that all problems involve people (including the analyst as being a person); and second, that people bring with them their personal and professional preferences and relationships. It can be argued that OR practice already has methods and approaches for problem formulation and critical analysis; for example, $\mathrm{CSH}$ in support of boundary critique and multi-perspectives on value; also System of Systems Methodology (SOSM) (Jackson, 2003) for matching method to problem-situation, respectively. This paper suggests that Staged Appreciation works around and within, so complementing and supporting, use of these methods. It also extends CSH to further support reflective practice, by asking those doing the analysis to appreciate their own OE/OM position on the issues/policies at stake. This is important for PSM and SOSM because the analyst and problem structurer need to appreciate their position in the situation. It acknowledges that eliciting people's beliefs is asking for almost impossible honesty and openness; however, people are more able to be open about what might surprise them if it were to happen, and 
also why they would be surprised. This can help to lead into more open discussion about where people are focusing their attention, to appreciate any narrow-ness of focus.

Referring back to Figure 2, CSH addresses values whereas Staged Appreciation acknowledges people's personal preferences and instituional preoccupations, which then become entwined with focus, sense-making and choice-making. So Staged Appreciation goes further into the personal spaces "where people are" and as such it can be both a preparation for $\mathrm{CSH}$-supported conversations and can act as an aid when using $\mathrm{CSH}$ as an approach. The shared appreciation by those involved can work towards those affected becoming involved through key people appreciating new shared interests. Having Staged Appreciation working around and within CSH, SOSM, PSM and OR/MS helps to shape relationships and create 'choose-able' conditions for realising shared interests, sustaining more open conditions for shared appreciation.

Staged Appreciation is proposed only as a guiding check-list to help to build techne for reflective practice when analysts are using systems-based techniques; and when using approaches, such as CSH, when looking at boundary issues and multiple perspectives; also, when selecting appropriate methods through SOSM. Indeed, it is this aspect of selection of analysis method that may need to be mindful of Staged Appreciation. This is the main theme of (Wright, 2013) where the key question is: "What reliable approach or method can be used to guide the selection of a suitable methodology or defensible combination of methodologies to help understand and resolve a complex problem situation?". The thesis points to the work of (Mingers and White, 2010) to describe how the SOSM approach has moved more towards combining systems methods, "[it] eventually moved from the question of selecting a single method, to recognising the value of combining together different methods, not just soft but especially employing both hard and soft methods together. This is known as multimethodology or coherent pluralism." It is the challenge of coherent pluralism that Staged Appreciation helps to address by drawing out the deep personal and relational bases that underlie people's purpose(s).

The illustrative case study shows that if those working to convene disparate people are able to work with and through the six themes of Staged Appreciation as a supporting trellis for developing their reflective practice, then (see p152 in Welsh and Fearn, 2008): “convening 
all relevant stakeholders in an explicitly open forum helped to bring to the fore a sense of underlying shared interests... The consultation managed to convert this shared interest into a shared appreciation that working together could lead to concrete results."

The soft systems techniques and the skilled practices of PSM and SOSM, to identify the problem and to select appropriate methods respectively, always remain at the centre of reflective practice. If they can be guided by Staged Appreciation, then that strengthens those reflective practices and supports $\mathrm{CSH}$, sustaining the emphasis on people and relationships. Given that the concept of choose-ables represents the imagined deemed possible, Staged Appreciation provides sustained conditions for the 'deeming' of new, innovative ways of working together. Where convening is deemed not to be possible, then CSH provides a supporting framework, with the Staged Appreciation 'check-list' being kept in mind for seeing any relational opportunities that may arise for collaboration.

\section{Conclusion}

Staged Appreciation acts as a reflective framework to provide a working check-list for guidance through a socially and personally complex problematic situation. Such a form of techne is arguably needed to complement OR analytical skills and competencies for selfreflective application of techniques. "Where people are" stands proud in the check-list because it is asking analysts to appreciate where people, including themselves, stand in terms of how they might be seeing the problem and making sense of their relationships. It also asks the analyst where they stand in relation to others; in particular, their clients.

OR analysts' skills and competencies lie in finding solutions to challenging problems. In socially complex situations it may not be possible to find a solution; it may only be possible to work towards a resolution. Staged Appreciation helps people to appreciate that relational conditions may need to be worked on. This could involve elevating the personal aspects, or re-focusing people to appreciate where they are in relation to each other, in order to see if conditions can be reached for agreeing shared interest (or purpose) through shared appreciation and for re-shaping relationships. An analyst may have to put their reputation as a problem-solver to one side and reflect on the need for further abstraction and a widening of the client-analyst and stakeholder-stakeholder relationships. Because Staged Appreciation is not a method, its limitations lie in the challenges posed by the people involved in the 
situation and in the natures of their relationships. All that Staged Appreciation is trying to do, as a guiding framework, is to keep people mindful of that.

The selected Systems Thinking techniques are presented simply as an illustrative example of how they can support analysis through this process of open appreciation. There is a plethora of techniques to choose from. These systemic ways of working are not entirely new (Mingers and Rosenhead, 2004). Systems Thinking techniques, guided by Staged Appreciation, supported by Shackle's work and Vickers' principles, and as embodied more recently by Nonaka's approach, together appear to add an insightful new dimension to knowledge sharing for understanding and reflecting upon the intricacies involved in socially complex situations.

It may be that analysts would prefer to develop their own techne 'check list' as a reflective 'handrail' to openness, and they may choose to use different techniques. What matters is that OR analysts begin to work more reflectively (Argyris and Schön, 1996) and support people in thinking more openly as we engage in the socially complex world.

\section{References}

Alston A and Dodd L (2009) Complex adaptive and inquiring systems theory for contemporary military operations: a multi-perspective approach, Proc. 26 ISMOR International Symposium on Military Operational Research, UK, September 2009.

Argyris C and Schön D A (1996) Organizational Learning II: Theory, Method and Practice. Reading, Mass.: Addison-Wesley.

Bar-Yam Y (2005) Making Things Work: Solving Complex Problems in a Complex World. NECSI Knowledge Press, Cambridge. See: www.necsi.edu Accessed 2017

Boin A, t'Hart P, Stern E and Sundelius B (2006) Politics of Crisis Management: public leadership under pressure, Cambridge University Press.

Bradshaw JM, Feltovitch PJ, Jung H, Kulkarni S, Taysom W, Uszok A (2004) Dimensions of adjustable autonomy and mixed-initiative interaction. In: Nickles M (ed) AUTONOMY LNAI 2969. Springer, Berlin, pp 17-39.

Checkland PB and Scholes J (2001) Soft systems methodology in action. in Rosenhead J and Mingers J (eds), Rational Analysis for a Problematic World Revisited. Chichester, John Wiley.

Checkland P and Winter M (2005) Process and Content: Two ways of using SSM, Journal of the Operational Research Society, Volume 57, No.12 
Churchman C (1967) Wicked Problems, Management Science, 4(14): pp141-142.

Cooperrider DL and Srivastva S (1987) Appreciative Inquiry in Organizational Life, in W.A. Pasmore and R.W. Woodman (eds) Research in Organization Development and Change, Vol. 1. Greenwich, CT: JAI: pp129-169.

Dodd L and Alston A (2009) Complex adaptive and 'inquiring' systems approaches for contemporary military operations. Cornwallis XIV Societal Conflict and Counterinsurgency, Vienna, April 2009

Dodd L, Alston A, Stamp G (2010) Staged Appreciation: looking out and in for black swans.15th Int. Command and Control Research \& Technology Symposium, USA. http://dodccrp.org/events/15th_iccrts_2010/papers/169.pdf accessed September 2017

Flood R L and Jackson M C (1991) Creative Problem Solving: Total Systems Intervention. Wiley: Chichester.

Heuer R J and Randolph H P (2015) Structured Analytical Techniques for Intelligence Analysis ( $2^{\text {nd }}$ Edition) CQ Press, Sage Publications.

Isaksen S G, Dorval K B and Treffinger D J (2010) Creative Problem Solving: a framework for innovation and change, 3rd Edition, SAGE Publications. ISBN1412977738

Jackson M C (2003) Systems Thinking: Creative Holism for Managers. Chichester: John Wiley \& Sons Ltd.

Jackson M C (2006) Beyond problem structuring methods: reinventing the future of OR/MS, Journal of the Operational Research Society, 57, pp868-878

Menzies-Lyth I (1988) Containing Anxiety in Institutions: Selected Essays, Volume 1.

Mingers J and Rosenhead J (2004) Problem Structuring Methods in Action, European Journal of Operational Research, 152 (3), pp530-554. ISSN 0377-2217

Mingers J and White L (2010) A review of the recent contribution of systems thinking to operational research and management science. European Journal of Operational Research 207 (3), pp1147-1161.

Monks T, Robinson S and Kotiadis K (2016) Can involving clients in simulation studies help them solve their future problems? A transfer of learning experiment. European Journal of Operational Research, 249(3), pp919-930.

Morgan G (1997) Images of Organisation. Sage: London.

Morgan G (1997) Imaginization: New Mindsets for Seeing, Organizing and Managing, (new management edition) San Francisco: Berrett-Koehler.

Nonaka I, Toyama R and Konno N (2000), SECI, Ba and Leadership: a Unified Model of Dynamic Knowledge Creation, Long Range Planning 33, pp 5-34. 
Ormerod R J (2008) The transformation competence perspective, Journal of the Operational Research Society, 59, pp1435-1448.

Ormerod RJ (2013) Research skills for the future: A consultant's perspective. Journal of Research Practice, 9(1), Article V2. http://jrp.icaap.org/index.php/jrp/article/view/380/305

Roberts N (2000) Wicked Problems and network approaches to resolution, International Public Management Review, Volume 1 - Issue 1 (http://www.ipmr.net)

Seagriff T and Lord S (2011) Soft Operational Research Techniques: Current and Future Uses, in YoungOR 17, 2011, pp. 40-53.

Shackle GLS (1957) Uncertainty and Business Decisions, 2nd Ed, Carter CF, Meredith GP and Shackle GLS (Eds) Liverpool University Press.

Sirett P and Dodd L (2006) Empirical Study to Investigate How Experience Relates to Understanding and Dealing with Strangeness, Naturalistic Decision-making 8, San Diego.

Taleb N (2008) The Black Swan: the impact of the highly improbable. Penguin.

Thompson M (2008) Organising and Disorganising: a dynamic and non-linear theory of institutional emergence and its implications. Triarchy Press.

Ulrich W (2003) Beyond methodology choice: critical systems thinking as critically systems discourse. Journal of the Operational Research Society, 54, No. 4, pp325-342.

Ulrich W and Dash DP (2013) Research skills for the future: Summary and critique of a comparative study in eight countries. Journal of Research Practice, 9(1), Article V1. Retrieved from http://jrp.icaap.org/index.php/jrp/article/view/377/304

Ulrich W (2017) If Systems Thinking is the Answer, what is the Question?

Discussions on Research Competence. http://wulrich.com/bimonthly_may2017.html

Vickers G (1983) Human Systems Are Different. Paul Chapman.

Welsh J and Fearn D (2008) Engagement: how public diplomacy in a globalised world. FCO. See Case Studies by Hudson L and Anstead A, pp145-159 http://webarchive.nationalarchives.gov.uk/tna/20080728082554/http://www.fco.gov.uk/en/a bout-the-fco/publications/publications/pd-publication/casestudies (accessed January 2018).

Williams B (2005) Soft Systems Methodology. The Kellogg Foundation, http://users.actrix.co.nz/bobwill (accessed February 2016)

Wright C (2013) Multiple Systems Thinking Methods for Resilience Research, MPhil Thesis, Cardiff University. https://orca.cf.ac.uk/45395/1/2013wrightrcmphil.pdf (accessed March 2018) 